\title{
FINDING THE GAPS: THE DEVELOPMENT OF A NETWORK FOR Graduate Attribute Professionals
}

\author{
Margaret Gwyn \\ University of Victoria \\ mgwyn@uvic.ca
}

\begin{abstract}
To help fulfill the Canadian Engineering Accreditation Board's new requirements, many institutions are creating positions focused on graduate attributes and the continual improvement process (GACIP). Due to the very recent development of this role, people hired as graduate attribute professionals (GAPs) have no established community in which to network and develop. In addition, the very nature of these positions is not well defined. This paper describes the development of the Graduate Attribute Professional Network, an informal community of people whose jobs are focused on GACIP, and the results of a survey conducted with its members. GAPs are found to generally be highly educated people, usually with an engineering background, many of whom have experience as educators. They tend to be new to their roles, to be spending $50 \%$ or less of full-time hours on GACIP-related duties, and to be involved in every aspect of graduate attribute assessment and the continual improvement process. GAPNet is an important resource to support these individuals who are so involved in engineering education and accreditation in Canada.
\end{abstract}

Keywords: Graduate attributes, accreditation, professional networks, graduate attribute professionals.

\section{INTRODUCTION}

When the Canadian Engineering Accreditation Board (CEAB) introduced the graduate attributes and continual improvement process (GACIP) requirements, it marked a major change to engineering accreditation in Canada. No longer was accreditation only a matter of inputs. Now, the accreditation process also included a focus on outputs: what have the students actually learnt, what data supports that observation, and what changes could be made to further improve their learning?

This change to the accreditation procedures of course necessitated change at Canadian engineering schools. The Engineering Graduate Attribute Development Project (EGAD) conducted snapshot surveys in 2013-2014 and 2015-2016 ([2,3]), asking schools about their approaches to graduate attribute assessment. In one question, schools were asked to rate the extent to which various structures, resources and features supported their process. In the 2013-2014 survey, 24\% of schools reported that "professional staff dedicated to assessment" supported their processes very much or quite a bit. By the 2015-2016 survey, this number had almost doubled to $47 \%$. In the words of the authors, "The greatest shift occurring between administrations [of the survey] has been the rise of specialized positions to help manage accreditation processes." ([3])

The role of graduate attribute professional (GAP) is a new one. No professional organization or formal network exists in which people newly hired to these positions can find support and guidance. The problem is compounded by the fact that there is no common understanding of the roles and responsibilities of a GAP.

In this paper I describe the creation of the Graduate Attribute Professional Network (GAPNet), an informal association for people whose jobs are focused on GACIP. I also discuss the results of a survey that was recently carried out with GAPNet members to learn more about both their positions and their professional backgrounds.

The survey results reported here will help Canadian engineering schools better understand how a GAP can support their GACIP activities; this could be beneficial both to schools that currently employ a GAP, and those who are considering hiring one. The results will also be of use to GAPs, to help them understand how their positions compare to others. Finally, this paper will hopefully serve as a way to grow the GAPNet community, increasing the support it can provide to GAPs across the country.

\section{THE GRADUATE ATTRIBUTE PROFESSIONAL NETWORK}

Talks and workshops on GACIP have been a part of the Canadian Engineering Education Association conference since its inception in 2010 (see, for example, [1]). The 2016 conference at Dalhousie University was no exception. After the conference, a small group of GAPs who had connected through these sessions decided to try and maintain and develop their professional relationship. Pooling their contacts, they invited colleagues from other 
schools to join them. This marked the beginning of GAPNet.

At the time of writing, GAPNet has 33 members from 17 institutions in 8 different provinces (a complete list of the schools represented in GAPNet can be found in Table 1). Members meet roughly once a month via videoconferencing. Discussion topics for the meetings are suggested by the members, and have included subjects such as assessing higher level attributes, using software systems to support assessment, and interpreting assessment results. Outside of monthly meetings, the GAPNet mailing list is used to disseminate information and announcements to the group, and as a way to gather information on GACIP practices at other institutions.

GAPNet is proving to be a useful way to tap into the pool of insight and experience of GAPs across Canada. The mailing list was used by EGAD to gather feedback on the current accreditation procedures in preparation for a meeting with CEAB. GAPNet is also helping to advance the development of GACIP best practices: GAPNet members were invited to submit a workshop to the Graduate Attribute and Curriculum Improvement Summit held at the University of Toronto in December 2016; and a collaboration formed out of GAPNet is facilitating a workshop on indicator redesign at the 2017 CEEA conference.

To learn more about GAPs and their duties, GAPNet members were invited via their mailing list to complete an online survey about their positions and their professional backgrounds in January 2017.

Table 1: Schools represented in GAPNet

\begin{tabular}{|l|l|}
\hline \multicolumn{1}{|c|}{ Province } & \multicolumn{1}{c|}{ Institution } \\
\hline British Columbia & $\begin{array}{l}\text { University of British Columbia - } \\
\text { Okanagan } \\
\text { University of Victoria }\end{array}$ \\
\hline Alberta & University of Alberta \\
\hline Saskatchewan & University of Regina \\
\hline Ontario & $\begin{array}{l}\text { Conestoga College } \\
\text { McMaster University } \\
\text { Queen's University } \\
\text { University of Guelph } \\
\text { University of Toronto } \\
\text { University of Waterloo } \\
\text { York University }\end{array}$ \\
\hline Quebec & $\begin{array}{l}\text { L'École de technologie } \\
\text { supérieure } \\
\text { McGill University }\end{array}$ \\
\hline New Brunswick & $\begin{array}{l}\text { University of New Brunswick } \\
\text { Université de Moncton }\end{array}$ \\
\hline Nova Scotia & Dalhousie University \\
\hline Newfoundland & Memorial University \\
\hline
\end{tabular}

\section{SURVEY RESULTS AND DISCUSSION}

When the GAPNet survey closed, $52 \%$ of members had completed the survey in full, with $61 \%$ providing at least partial responses. The results of the survey are presented below.

\subsection{About the GAPs}

To gather information about what sort of people fill the GAP role, the survey asked a series of questions about the professional backgrounds of GAPNet members. First, the survey asked about educational background; the results are shown in Fig. 1. GAPs tend to be highly educated individuals, usually coming from an engineering background. Just over $50 \%$ of respondents hold a $\mathrm{PhD}$, with another $35 \%$ holding a Masters as their highest degree. Approximately $70 \%$ of these degrees are in various engineering fields, with the rest in science, education or business. Two respondents also reported they had degrees in progress (a $\mathrm{PhD}$ in engineering and an MA in education).

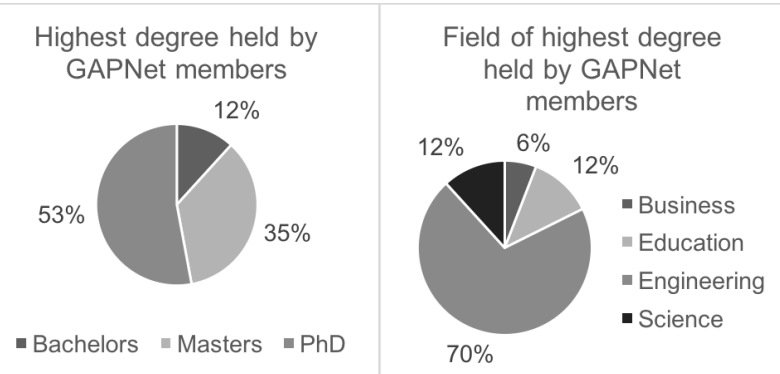

Figure 1: Educational background of GAPNet members

Interestingly, almost $30 \%$ of respondents have a degree in Education, at either the Bachelors or Masters level. In most cases, this is in addition to a science or engineering degree.

The survey also asked about work experience prior to taking on a GAP role. The results are shown in Fig. 2. Most respondents have held more than one position before taking up their current GAP duties, so the sum of the percentages does not add to $100 \%$. The two most common prior roles were teaching at the post-secondary level, and working in various staff roles in post-secondary institutions, with almost $50 \%$ of respondents reporting being involved in one or the other of these jobs. The next most common responses were working as a post-doc or research assistant, teaching in the K-12 system or in informal education, and working in the engineering industry.

While obviously rooted in the academic and engineering fields, GAPNet members bring a wide range of backgrounds and training to their tasks. With such a diversity of people working on the problems of GACIP, novel approaches are sure to result. 


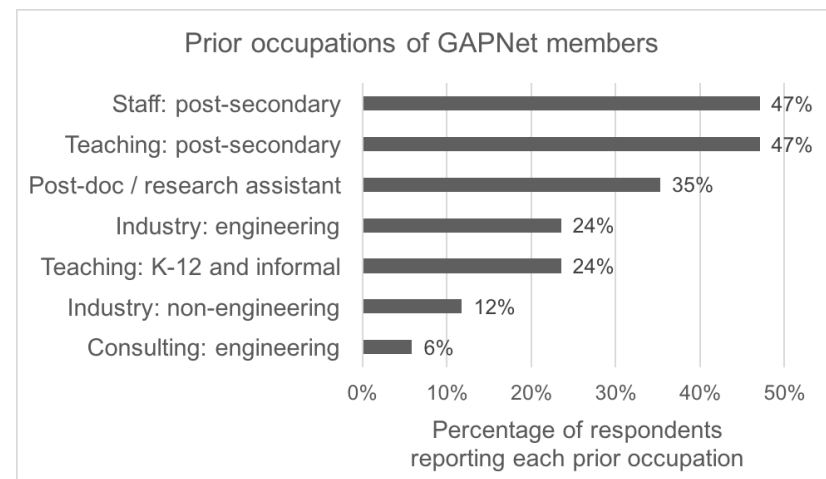

Figure 2: Prior occupations of GAPNet members

Finally, GAPNet members were asked how long they had been employed as GAPs. The results are shown in Fig. 3. At the time of the survey, $76 \%$ of respondents had been in their current positions for less than 2.5 years. These results are unsurprising, given that $\mathrm{CEAB}$ only introduced the GACIP requirements recently. However, it does emphasize just how recently this field of work has developed.

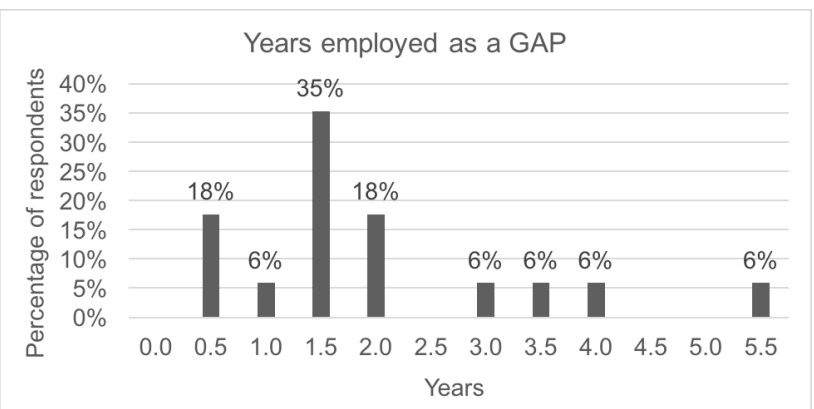

Figure 3: Years employed as a GAP

\subsection{About the GAP position}

GAPNet members were also asked questions about the nature of their work. The scope of GAP positions was very evenly divided, with $50 \%$ of respondents working for a specific department or program at their institution, while the other $50 \%$ worked at the faculty level supporting all departments and programs.

When analyzing the duties reported by respondents, it becomes obvious that GAPNet members are involved in every aspect of GACIP. Using EGAD's six step guide ([4]) as a framework, these duties include:

1) Defining program objectives and indicators

- Develop overall strategy and create long-term plans

2) Mapping the curriculum

- Work with instructors to develop and/or map learning outcomes in their courses

- Create or coordinate the creation of curriculum maps

- Maintain curriculum maps
3) Collecting the data

- Create and customize rubrics for attribute assessment

- Work with instructors to develop assessment strategies

- Design and implement surveys and other indirect assessment measures

- Develop methods to assess learning during cocurricular activities like co-op work placements

- Research and develop new assessment methods, especially for higher-level attributes

- Oversee the collection of data

- Monitor the data collection for completeness

4) Analyzing and interpreting the data

- Aggregate data and produce reports

- Organize meetings to review data

- Create and deliver presentations on assessment results

5) Improving curriculum and process

- Make continual improvement recommendations

- Monitor programs' progress on their curriculum improvement plans

- Create and deliver presentations on curriculum improvement progress

6) Managing and implementing change

- Organize meetings and workshops related to GACIP

- Educate instructors and administrators on the principals of GACIP

- Provide training and advice on teaching and assessment to instructors

- Monitor and communicate latest CEAB requirements and GACIP best practices

- Hire and supervise short-term staff (e.g., work study students) to assist with GACIP-related tasks

- Oversee development of software systems to support GACIP

Unsurprisingly, GAPNet members also reported being involved in preparing accreditation documentation.

Because of the way this question was asked (free-form text field), it is not possible to report what percentage of respondents are involved in each duty. This could prove an interesting topic for further investigation. Regardless, the results show that GAPs can be a versatile and valuable resource to engineering programs.

GAPNet members were also asked what percentage of a full-time position their GACIP duties entailed. The results are shown in Fig. 4. Just over a quarter of respondents have a full-time position dedicated to GACIP, while just over half spend approximately $50 \%$ of a fulltime position on these duties. The remaining respondents report $30 \%$ or less of a full-time position spent on GACIPrelated tasks.

When asked what non-GACIP duties they were responsible for (Fig. 5), just over one-third of respondents reported they also taught at their respective institutions. The next most common response was curriculum review and development, with almost $20 \%$ reporting these 
responsibilities. Other tasks performed by GAPs include: research; data analysis and management; recruitment and management of transfer students; other departmental service; and management of internal quality assurance processes. Some respondents have more than one responsibility in addition to their GAP duties, and some have none, so the sum of the percentages does not add to $100 \%$.

Most of these additional duties are closely related to GACIP topics; a GAP employed in one of these dualresponsibility positions will hopefully be able to draw on their experiences in one role to inform their work in the other.
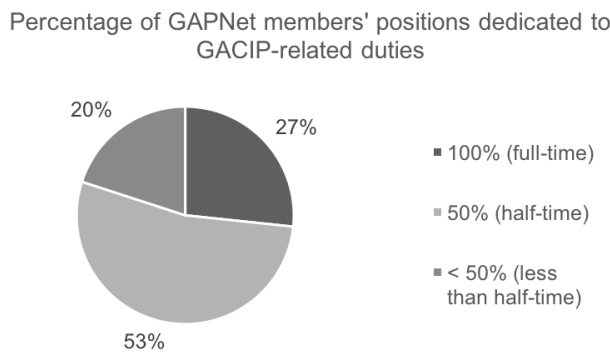

- $100 \%$ (full-time)

$-50 \%$ (half-time)

$-<50 \%$ (less

than half-time)

Figure 4: Percentage of GAPNet members' positions dedicated to GACIP-related duties

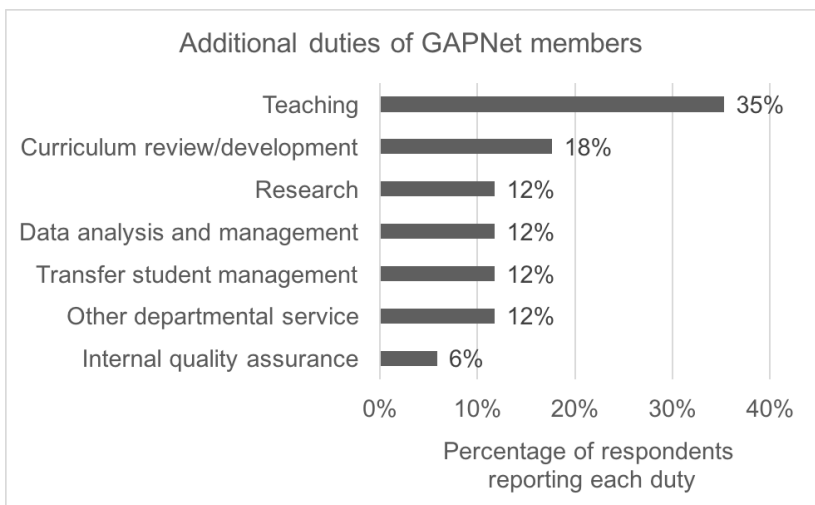

Figure 5: Additional duties of GAPNet members

\section{CONCLUSIONS}

CEAB's graduate attribute and curriculum improvement requirements are here to stay. So, presumably, is the role of the GAP. As the number of GAPs continues to grow and their duties continue to evolve, GAPNet hopes to grow and evolve with its members. GAPs who are interested in contributing to a community of support and professional development are encouraged to contact the author. Together, we can improve how Canadian engineering schools approach graduate attribute assessment and the continual improvement process; by extension, we can improve the education of engineering students across the country.

\section{Acknowledgements}

The author wishes to acknowledge the members of GAPNet, for providing the data that is reported in this paper, and for creating such a knowledgeable and supportive community.

\section{References}

[1] Engineering Graduate Attribute Development Project, "6Step Guide". Available as of June 4, 2017 from http://egad.engineering.queensu.ca/

[2] Jake A. Kaupp and Brian M. Frank, "EGAD National Snapshot Survey", in Proc. CEEA Canadian Engineering Education Conf., (Canmore, AB; 8-11 June 2014), 2014. Available as of May 7, 2017 from http://egad.engineering.queensu.ca/wpcontent/documents/EGAD\%20National\%20Snapshot $\% 20 \mathrm{Su}$ rvey $\% 20$ Presentation.pdf

[3] Jake A. Kaupp and Brian M. Frank, "EGAD National Snapshot Survey: Change, Progress and Improvement", in Proc. CEEA Canadian Engineering Education Conf., (Halifax, NS; 19-22 June 2016), 2016. Available as of May 7, 2017 from http://ojs.library.queensu.ca/index.php/PCEEA/article/view/ 6503

[4] Warren Stiver, Andrea Bradford, Sheng Chang, Khosrow Farahbakhsh, David Lubitz, Joanne Ryks, Bill van Heyst, Hongde Zhou, and Richard Zytner, "Engineering Graduate Attributes - Investigation", in Proc. CEEA Canadian Engineering Education Conf., (Kingston, ON; 7-9 June 2010), 2010. Available as of May 7, 2017 from http://ojs.library.queensu.ca/index.php/PCEEA/article/view/ $3143 / 3081$ 